\title{
„Dag” in die eerste hoofstukke van Genesis
}

In 'n vorige artikel' het ek reeds die betekenis van die begrip „dag" aangesny en die volgende samevatting daarvan gegee: Die begrip ".dag" in Gen. 1:5 kry dus nie sy betckenis deur sy teenstelling to .duisternis" nie. maar deur sy positiewe inhoud van liggewing, d.w.s. sy vormgewende, identiteitsverskaffende werking wat die geheel van die verbinding: skeppingswerk-aand-more domineer. Dit het dus nic 'n apologetiese stempel nie, maar 'n sterk tetiese, positiewe, vitale betekenis.

Daar word ook nog verdere lig op die begrip ..dag" gewerp deurdat dit telkens ná Cool se skeppingsdaad(e) herhaal word. Dit kom in die volgende ritme voor: „En God het . . . gemaak. Toe sien God dat dit goed was. En dit was aan en dit was more. die . . . dag". M.a.w. die begrip ,dag" ontvang sy betekenis vanweë die geladenheid met Gods optrede. Dit is nie 'n blote tydspan, nic iets neutraals nie. En die dae behou ook selfs daarna iets van daardic Goldelike geladenheid, soos duidelik blyk uit die motivering van die sewende dag se heiliging: „ondat $\mathrm{Hy}$ daarop gerus het van al Sy werk wat Cod geskape het deur dit te maak". Hiermee word die ses dae se werk in verband gestel met Cod, sodal dit nie nou los van God staan as iets van die verre verlede nie. Tegelyk word deur die heiliging van dié dag, d.w.s. deur die afsondering aan (iol. en die seëning daarvan. getoon dat dit nie slegs vir (jod alleen bedoel is nie. maar dat dit ook met die wêreld in verband staan." Die Sabbatsgeborl (Ex. 20:8) toon dat dié Gorddelike geladenheid van die dae nog steeds van betekenis is.

Nog 'n kenmerk van die begrip ..dag" in (ien. 1 is die historiseringshetekenis daarvan. (ien. I verhaal nie slegs dat plante. diere. ens. deur God geskape is nie. Daar word ook nie slegs verskillende skeppingsdade van (jod gegee nie; ook word nie slegs gesê dat dit in ses dae gedoen is nie, maar elke dag word bepaaklelik genoem met sy bepaalde inhoud, met sy temporele verloop (skeppingsdaad-aandmore) en met sy bepaalde plek in die ry van die skeppingsdae (tweede. derde, ens.). Hieruit blyk duidelik Jat elke dag sy besondere identiteit het (chronologies, temporeel en inhoudelik) en andersyds deel vorm van ' $n$ verloop van dinge. m.a.w. 'n historiese verloop. ${ }^{3}$ Die skepping is dus ' $\mathrm{n}$ histories gewordene van (deur) Cool.

Dit staan dus in skerp teenstelling tot alle tydlose en mitiese opvattings van die skepping soos byvoorbeeld by Israel se bure in swang was. So sê Von Rad byvoorbeeld": .The inclusion of crealion within a series of days provides the last possible delinitation to every kind of mythical thinking. The events that are recorded happened once for all and their results are irrevocably permanent. The seven days are unquestionably to be understood as actual days and as a unique, unrepeatable lapse of time in this world. "Treation as Cod's work inaugurates time and thus the temporality and finiteness of the world' (E. Osterloh). Genesis, ch. 1. begins the work of history. 
which continues to the revelation of Sinai and the tribal conquest. The author does not speculatively develop a cosmogonic drama, which he can follow with interest as though from a detached point of observation. Rather. his point of reference is wholly within time and within creation, to the coming into being of which he attests ...."

Ook die taalgebruik benadruk die skeppingswerk as historiese saak aangesien die beskrywing gegee word in konsekutiewe werkwoorde. m.a.w. volgens die beskrywingsmetode waaraan die geskiedskrywing voorkeur gee.

"n Verdere kenmerk van die begrip „dag" is dat dit parallel loop aan ..wajjömèr" (en God het gesê). Dit kom telkens voor in die ritme: ..En Cood het gesêe . . . . En dit was aand en dit was môre, die . . . . dag". Die woord ...wajjömèr" (en God het gesê) is blykens Joh. $1: 1$ (..in die begin was die Woord .... alle dinge het deur Hom ontstaan ....") baic sterk teologies gelaai. Dit is nie slegs "n blote aankondiging of voorneme van Gol nie. maar Sy skeppende magswoord. Vergelyk ook byvoorbeeld Ps. 33:9: .. want Hý het gespreek, en dit was; Hý het gebied, en dit staan". Hierdie skeppende magswoord word telkens opgevolg deur ..dag": ons kan eintlik sê ..dag" is die antwoord op die Doord. Of omgekeerd: ..dag" kry sy bestand deur die Woord.

By die sewende dag kry ons "n belangrike verskil met die ses dae. Ferstens let ons daarop dat die woord ..dag" hier nie slegs een keer nie. maar drie mal gebruik word. Waar die begrip ..dag" "n Goddelike geladenheid het. word dit by die sewende dag dus tot die klimaks van (joddelike gelarlenheid opgevoer. Hierdie feit word dan ook uitdruklik gestel deurdat die sewende geseën en geheilig. d.w.s. vir (iol afgesonder. word t.w.v. die rus na die sesdaagse arbeid. D.w.s. die sewende dag het die geladenheid van al ses dae gekry.

Daarmee word die gelatenheid van die ses dae ook weer eens gestel. nou nie die dae indiwidueel nie. maar kollektief: in hulle samehang as ses dae. d.u.s. die geheel van (iod se skeppingsdade. Hier deur word nog in verdere belangrike faktor deur die sewende dag heklemtoon. nl.: dit weerspieël die eenheid van die sesdaagse skeppingswerk en toon dat dit hierdic eenheid bepaald in God vind. So wys (alvyn in sy kommentaar op Cienesis daarop dat God ses dae aan die skeppingsarbeid bestee om sodoende elke dag met Homself te vul.

Vervolgens sien ons dat hier gepraat word van .,op die sewende dag". Nêrens hy die sesdaagse skeppingswerk is gepraat van ..op die soveclste dag" nie. ..Dag" is nie "n opsigselfstaande grootheid waarop of waarbinne (iod Sy werk verrig nie. d.w.s. wat enige perke (soos tydsbeperking) aan (iod stel nie. Nee, (iod is soewerein daarbowe. ..Dag" kry sy bestand eers deur die optrede van God. Hy skep nie ..op" dié of daardic dag nie. of, duideliker gestel. in negaliewe vorm. Hy skep nie voordat die aand aanbreek nie. maar Hy skep. en as Hy geskep het. worl dit aand en more en kry die dag sy besiag. 
(Hiermee word nie gesê dat ,.dag” geen vaste tydspan gehad het nie, slegs die logiese verhouding word gestel, nl. dat die inhoud nie bepaal is deur dic ,dag" nie: die "dag" was daar en God het geskep (Hy moes skep), maar die ..dag" word bepaal deur die inhoud, nl. God se skeppende optrede; God se skeppende optrede het die ..dag" sy bestand gegee.)

Nadal die skeppingswerk van die ses dae voltooi is, nadat dit dus duidelik gestel is dat die dag sy bestand kry deur God se doene. kan daar nou van ,die sewende dag" gepraat word sonder gevaar dat dit as 'n opsigselfstaande grootheid teenoor God gesien sal word.

Voorts is dit opvallend dat die sewende dag nie met ..uand-môre" afgesluit word nie. Dit beteken nie dat die sewende dag nie gecindig het" nie. Immers, daar word duidelik gepraat van die sewende ..dag". En uit die sexdaagse skeppingswerk is dit duidelik dat ..dag" die omsluiting is van: Gods daad-aand-môre. Tog is die weglating van .aand-mốre" nie toevallig nie, maar doelbewus." Hiermee word aan die sewende dag 'n .,opheid" na die kant van die volgende, d.w.s. die (opvolgende) geskiedenis gegee, waardeur dit aan die begin van die geskiedenis geplaas word, m.a.w.. daarmee word tegelyk enige sikliese denke as sou die sewedaagse skeppingswerk steeds herhaal word, by die wortel afgesny.

Terwyl die sewende dag so sterk aan die ses dae gebind is en dit die skeppingsdade daarvan op 'n besondere wyse saamtrek, d.w.s. die geladenheid van al ses dae verkry, word. met die verbinding van die sewende dag aan die geskiedenis, tegelyk die hele skeppingswerk (= al die skeppingsdade) an die geskiedenis rasgekoppel. Die skeppingswerk van God staan nie los van die geskiedenis, van die daaglikse gebeure nie. En omgekeerd staan die geskiedenis, die gebeure nic los van die skeppingswerk van God nie: die geskiealenis is 'n geskiedenis van die geskape dinge en word ewe-eens deur God gedra en vind sy doel in heiliging en verheerliking van (iod.

Daar is dus 'n eenheid van skeppingswerk en geskiedenis. Vanwee hierdie eenheid kry ons voorts $n$ nog sterker saamtrekking as in die Sabbat. waar ses dae as't ware in een dag geprojekteer word. nl. in Cien. 2: 4 waar die hele tydperk d.w.s. die ses dae, gesien word as "die dag toe Jahwe (iod die aurde en die hemel gemauk het". (Die woord ..dag" word dus blykbaar met opset gebruik .... nic slegs die gewone uitdrukkingswyse: .toe Jahwe God die aarde en die hemel gemaak het" nie.) En dit word spesifiek as die begin van die mensdom se geskiedenis - soos dit in die Paradys tot openbaring gekom het - gestel. Dit lui byvoorbeeld: .Dit is die geskiedenis van die hemel en die aarde toe hulle geskape is. Die dag toe Jahwe God „lie aarde en die hemel gemaak het, was daar nog geen struike

Bogenoemde stelling bly geld al sou die beginwoord: ..Dit is die geskiedenis ('êllè tôledôt) van die hemel en die aarde toe hulle geskape is", as onderskrif van Gen. 1:1-2:3 geld, 'n verklaring wat deur Aalders ${ }^{7}$ kragtig bestry word op grond van twee faktore: eerstens. dic gebruik van die woord ,"èllè" (dit) wat gewoonlik op die opvolgende dui en nie op die voorgaande nie; tweedens, die gehruik van die woord 
„töledôt" (geskiedenis) wat eintlik ..nakomelinge. generasie" beteken en dus nie die ..ontstaan" of ...wording" van die wêreld kan aandui nie. maar wel die ..geskiedenis" van die wêreld wat reeds deur God geskape is.

Ons kan hier nog byvoeg dat Aalders se standpunt ook gesteun word deur die besonder sterk parallel van Gen. 2:4 met 5: I waar ..die dag toe" (bejôm) gebruik word onı ..töledôt' (hier ..stamboom”) met die opvolgende te verbind: ..Dit is die stamboom (tōledôt) van Adan. Die dag toe God Adam geskape het. het Hy hom gemaak na die gelykenis van Cod ..."., en dan volg die stamboom (vgl. daarvoor die bespreding van dié gedeelte hieronder).

Selfs al sou die Paradysgeskiedenis by $2: 4 \mathrm{~b}$ begin, $n l$ met ..Die dag toe God die aarde en die hemel gemaak het", dan word die skeppingswerk nog as die begin van die mens se geskiedenis gestel. soos die skakeling met die volgende woorde aandui ,.(toe) was daar nog geen struike ...." (Daar word byvoorbeeld nie gesê ..nadat" (jod die aarde en die hemel genaak hel, was daar nog geen struike nie.)

(Voorts behels .,dag" hier ook dan nog dic sesdaagse skeppingswerk want die woorde ..die dag toe ...." teken die situasie tot en met die skepping van die mens, m.a.w. dit het betrekking op vs. 5 , 6 én 7. En dan maak dit weinig verskil of ons vs. 5 en/of 6 sien as tussensin, sodat die beskrywing van die skepping van die mens in vs. 7 by vs. 4 aansluit. en of ons vs. 4 neem as opskrif van die geheel.")

Terwyl Gen. 1: 1 die skrywer of leser in die gees verplaas tot voor die geskiedenis (., in die begin"). plaas (ien. $2: 4$ hom met die woorde ,die dag toe" (bejôn cà̌ôt jahwè) konkreet midde in die raamwerk van die geskiedenis. Die woord ..op die dag" (bejôm) behels iets wat reeds geskape is en dus reeds bestand het. Die skrywer neem sy stanplek dus in die geskiedenis. Hy sien Gods werk soos dit in die geskiedenis geset is, of. anders gestel: hy spreek .,histories". Die infinitivus constructus ..bejôn cišnt jahwe” rop die dag van die skeppe van Jahwe) lé dan ook die nadruk nie so slerk op die daad as aksie nie. maar meer on die daad as gebeure." en hier well historiese gebeure.

Vanweë die besondere eenheid van die skeppingsdae -- in eenheid wat hulle benaaldelik in (ioll vind -. word die term ,.dag" dus nok gebruik vir die samevatting van meer as een dag wat in bepaalde eenheid van (iods ontrede vorm. Die woorde .die dag toe" in Gen. $2: 4$ is dus nie 'n skema of " $n$ kader nic. en beteken slegs .10e". maar dan baie sterk inhoudelik en veral histories gelaai.

(lit dic voorgatande bespreking is dit dus duidelik dat die verskillende gehruike van die term .dag" in Gen. 1:1-2:4. nl." as daglig $(1: 5)$. dag wat afgemerk is deur aand en môre $(1: 5)$, dag as teenstelling lot nag (1:14). 'n dag van vier-en-twintig uur (..vir dae ... jare". 1:14). die hele periode ${ }^{12}$ van Gods skeppingswerk $(2: 4)$. nie ' $n$ teken van willekeurigheid' ${ }^{12}$ is nie, ook nie van wispelturige 
vloeibaarheid van betekenis nie. Inteendeel, in elk geval het die woord sy bepaalde. afgebakende betekenis, maar $\log$ is daar 'n basiese eenheidsgedagte sodat die term gebruik (kan) word on die verskillende inhoude aan te dui.

Samevattend kan ons dus oor die begrip ..dag" in (ien. 1:-2:4 die volgende sê:

Dit het nie 'n apologetiese stempel ( $=$ teenoor Juisternis of nag) nie. maar 'n sterk tetiese, positiewe, identiteitgewende. vitale betekenis. .Dag" word beheers deur die gedagte van sterk (joddelike geladenheid (gevul met Gods optrede. of, beter, produk van (jods optrede).

Dit het ' $n$ historiseringsbetekenis, d.w.s. dit bestenpel die inhoud daarvan as iets wat geskiedkundige verloop en betekenis het.

„Dag” (en ewe-eens die geskiedenis) word gedra deur die Cioddelike (nags-)woord.

„Dag" impliseer 'n basiese eenheid in gebeure of geskiedenis. Daarom word dit ook gebruik vir die samevatting van meer as een dag wat 'n bepaalde eenheid van Gods optrede vorm.

Daar is egter geen wispelturige vlocibaarheid van betekenis nie. In elke besondere geval het die woord sy bepaalde. afgebakende betekenis wat uit die verband bepaal kan word.

Die begrip ..dag" is dus teologies bepaal en nie kosmologies of antropologies of antropesentries nie. Dit is nie maar die resultaal van natuurgebeure nie." (Ook is ..dag", en so ook geskiedenis. nie resultaat van die menslike optrede nie. ..Dag" en geskiedenis word bowe-al deur Goul bestand gegee en gedra -- dit was reeds daar voor die mens op die toneel verskyn het.

(FEN. 2:17 $\% / g$. Dit is nodig om ook op die verdere gebruik van die woord .dag" in Genesis te let.

Ook in Gen. 2:17 vind ons die woord ,jôn" (dag) en wel in die sin: .die dag as jy datarian eet, sal jy sekerlik sterwe". Die begrip ..dag" moet hier nie soseer gesien word as tydsaanduiding. asof die mens onmiddellik sou neerslaan en sterwe nie. .Dag" druk log nie momentele optrede uit nie. Voorts maak dit ook nie veel sin as ons sou aanneem dat dit tydens die duur van die dag sou plaasvind nic. Waarom duur dit dan 'n dag lank?

Ook moet ons die sin nie hipoteties verstaan nie. Immers, dan sou ons 'n inperfektumvorm van die werkwoord verwag: ook nie verklarend nie (die feit van die daad) want dan sou ons "n perfektum verwag. ${ }^{15}$

Voorts dien ..dag" nie om die sekerheid van die dreiging te benadruk nie. Dit is genoegsaam vervat in die inf. absolutus-konstruksie .môt tämût" (sekerlik sterwe). (Ons het te doen met 'n inf. constructus plus , jöm”, net soos in Gen. $2: 4$. Dit lees: .,bejom äkolka mimmènnû", lett.: .op die dag van jou eet daarvan". En net soos in Gen. 2:4 sien dit op die historiese karakter van die mens se oortreding. dit is "n historiese vergryp. Die begrip ..dag" plaas die daad dus konkreet in die geskiedenis. dit bring ons konkreet by die inhoud. 
by dic (joddelike geladenlieid. Dit is "n aantasting van die dag, die geskiedenis. Of anders gestel: dit is 'n epogmakende daad.

Die konstruksic keer terug in Gen. $3: 5$ in die woorde van die slang aan die vrou: .bejôm "ảkolkìm mimmènnû": .die dag as julle daarvan eet". Hier is dit ewe-eens ,jôm" (dag) plus inf. constructus, dus lell.: ..op die dag van julle eet daarvan". Ook hier is dit duidelik dat ..lag" nie oombliklikheid aandui nie. maar die historiese. epogmakende karakter van die daad. Die geskiedenis sal in wese verander word. En dit sal nic 'n vergryp wees nie, maar in (historiese) deurbraak vir die mens.

Die begrip ..ken" (jdc) is vir die Hebreër nie soseer 'n intellek. luele en dus momentele iels soos by ons Westerlinge nie, maar meer in konkrete kenne. dus 'n kenne deur ervaring. Hierdie feit spreek ook baie sterk léén die temporele opvalting van ,.dag", en vir die ..historiese". cpogmakende: ..die dag van julle eet daarvan sal julle oë oopgaan sodat julle soos (jod sal wees deur goed en kwaad te ken".

In die konstruksic van ..jôm" + inf. constructus lê daar dus "n belangrike betckenis opgesluit wat ongelukkig deur die Afr. V. oor die hoof gesien is met die neutrale vertaling: ..God weet dat as' julle daarvan eet".

Dit is interessant dat die vrou nie die konstruksie gebruik nie. Sy stel dit eenvoudig as: ..julle mag daarvan nie eet nie . . . . anders' (pen temultûn) sal julle sterwe". Hoewel sy die skerple van die dreiging oordryf met die woorde ..en dit me aanroer nie", sien sy blykbaar nie die diepte van die saak. $\mathrm{nl}$. dic historiese van die vergryp, raak nie. Sy voel: die verbod is erg. maar die oortreding nie!

Die verdere geskiedenis toon dat die mens gefaal het in sy opdrag om die natuur te beheers. In plaas van dit te beheers. het hy hom daaraan vergryp. Daarom word hy ook juis in sy beheersing van die natuur getref. Dic aarde word vervloek en die mens word gedegradeer tot beheerser van 'n vervloekte aarde. Daarby word sy harmonic met die aarde versteur: hy verkeer nou in 'n strydende. worstelende posisie met die aarde. Hy wat onbeheersd van die aarde geëet het, sal nou, .met moeite" daarvan eet (Gien. 3:17).

Opvallend dat die mens juis in die ,eet" getref word. Dit loop parallel aan lie adrd van sy oortreding. Daarby hang ..cet" saan met die lewe as lewensbehouder en -versterker. Deurdat hy in sy eet aangetas word. word sy lewe dus op wankelende bene gestel. Nog in klein stappie verder, en die lewe self is getref. Hierdie verdere stap lê opgesluit in die woorde: .al die dae ran jou lewe".

Datar is "n besliste wysiging in straf. maar die straf word nie afgewend nic. Dic lewe word wel voortgesit. maar onder die skadu van die dood: ..met mocite sal jy daarvan eet al die dae van jou lewe". Die verbinding van hierdic woorde toon: die lewe staan onder oordeel (..moeite") en loop uit op die dood (..al die dae van jou lewe").

Dit kom veral duiclelik uit in die parallelle woorde wat volg: ..tot. dat jy terugkeer na dic aarde. Want daaruit is jy gencem. Want stof 
is jy, en tot stof sal jy terugkeer" (Gien. 3:19). Dic dood word nou gesien as "n inherente, ,natuurlike" iets. in dié sin dat dit van nou af aan die gewone (natuurlike) weg is. Die lewe loop vanuit stof tot (terug na) stof.

Dit is opvallend dat die woord ..dag" nie hier gebruik word nie. soos wel in die strafdreiging in Gen. 2:17 en in die woorde van die slang (Gen. 3:3). Dus nie: ..tot die dag van jou terugkeer na die aarde" nie, maar ,, totdat' jy terugkeer" (cad šûbckī). Die terugkeer na die aarde word dus nie gesien as 'n epogmakende saak nie. Dit is nie "histories" (in die sin van 'n historiese insnyding, vgl. ons uitdrukking: ,dit is 'n geskiedkundige oomblik") nie, maar 'n geleidelike proses vanaf die eet van die verbode vrug. Dit is dus reeds vervat in die woorde: .,al die dae van jou lewe". Die dood is nou maar slegs die finale, voltooide voltrekking. (Die epog het reeds met die eet van die vrug aangebreek.) Dit geskied sonder rimpeling op die historie: „totdat jy terugkeer”, van stof tot stof . . . . !

Dit val mens op dat die strafvoltrekking (Gien. $3: 17$ ) tot die strafureiging (Gen. $2: 17$ ) in die volgende parallel staan: .dag-eetsterwe" en ,eet-dae-lewe". .Dag-sterwe" word dus .,dac-lewe". In sekere opsig dek die begrippe mekaar. soos hierbo aangedui, nl. dat die sterwe reeds as't ware begin intree het by die eet van die verbode boom. Voorts skyn die meervoud ..dae" in dic strafvoltrekking "II besondere betekenis te hê. Dit word sterk gekoppel aan die idee van moeite: ., met moeite sal jy daarvan eel al die dae van jou lewe". Die uitdrukking benadruk die lewe in sy konkreetheid. inhoudelikheid of geladenheid, en wel in sy geindiwidualiseerdheid (verskillende dac). Maar hierdie geindiwidualiseerdheid verskerp tot gebrokenheid: die lewe bestaan nou uit 'n hoeveelheid dae, ma.w.. dit is 'n verganklike. gebroke lewe. Dit is geen eenheid meer nie, geen lewens-..dag" nie. maar 'n gebrokenheid of gedisintegreerdheid van lewens-,.dae". Ons vind dieselfde ongunstige betekenis in ons uitdrukking: ..daar het ek ,dae' gehad". Vergelyk ook Jakob se woorde aan Farao (Cen. 47:9): „Die dae van die jare van my vreemdelingskap is honderd-en-dertig jaar. Min in getal en vol teëspoed was die dae van my lewensjare en hulle het nie gehaal by die dae van die lewensjare van my vaders gedurende die dae van hulle vreemdelingskap nie".

Nog 'n opvallende feit van die sondeval-geskiedenis is dat nie slegs die woord ..dag" in die strafvolirekking ontbreek nie (plek gemaak het vir ,dae"). maar ook die woord ,.sterwe". Dit word nie in die toekoms gestel in "n aankondiging soos: ..jy sal sterwe" nie (die sterwensepog het immers reeds aangebreek met die verbode eet); egter ook nie in "n perfektum-sin soos: ..nou het jy gesterwe" of „.begin sterwe" nie. Tog word dit duidelik beheers deur die gedagte van dood en dit wat tot die dood voer (vgl. ,met moeite sal jy daarvan eet". ..al die dae van jou lewe". .totdat jy terugkeer" (Gen. 3: 17-19)). Dit is asof die verskuilde genade van Giod oor die atmosfeer hang en dic moontlikheid van iets anders as sterwe. iets soos 'n misterie impliseer.

Die gebruik van ..dag" in (ien. 4:14 werp weer eens vir ons

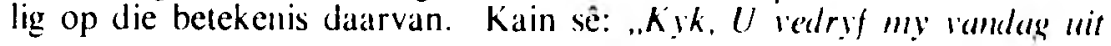


die land uit". Ook hier is dit duidelik dat ..dag" die historiese karakter van die daal wil aandui. Kain sê sogoed as: hiermee word my geskiedenis aangetas. dit is 'n epogmakende gebeurtenis. Net soos in (jen. 3:5, hel dic Afr. V. by hierdie betekenis egter verbygesien en neutraal vertaal met: ..Kyk, "I verdryf my nou" uit die land uit".

Die gebruik van ..dag" in die volgende gedeeltes is "n bevestiging van ons beskouing oor die betekenis daarvan en werp ook nog verdere lig op die saak. Die geslagsregister ran (jen. 5 begin met: „Die dag toe (iod Adam geskape het. het $\mathrm{Hy}$ hom gemaak na die gelykenis van God. Man en vrou het Hy liulle geskape en hulle geseèn en hulle mens genoem. dic dag toe hulle geskape is". Hier vind ons weer dieselfde konstruksie (nl. inf. constructus) as in (jen. 2:17 en $2: 4$. Dit lui: ..bejom berō “èlōhîm “ādām” = (lett.): .op die dag van die skeppe van God Adanı .... "en ..bejôm hibbāre’ān" = (let1.): ..op die dag van hulle geskapenheid".

Hier kom dit veral duidelik uit dat ..dag" nie bloot "n temporele betekenis het nie: immers, dan sou die tweede sinsnede met ..dag" heeltemal oorbodig wees. nl. die woorde: ..die dag toe hulle geskape is". Dit kan to:! nie "n ander dag wees nie! En waarom dan die herhaling van ..dag"'?

Die sin word duidelik as ons ..dag" neem in sy ..historiese". ..epogmakende" betekenis. Dan word die begrip ..dag" hier aan die begin gebruik en deur sy herhaling aangewend on te beklemtoon dat dit " $n$ besondere epog was in die menslike bestaan. in sterk teenstelling tot die mens se verdere lewensverloop.

Hierdie verdere verloop van die menslike geskiedenis word geteken in die refrein: "so was dan al die dae van ... .". Dié woorde staan in sterk parallel met 3:17 waar aan die mens gesê word dat hy met moeite sal eet ..al die dae van jou lewe". Ook hier blyk dus dat die meervoud ..dae" gebruik word on die gebrokenheid, gedisintegreerdheid van die menslike lewensverloop aan te dui. Dié woorde word dan ook in sterk verbinding opgevolg deur ..en hy het gesterwe". asof die lewensdae disintegreer lot sterwe. Daarmee word die dradgdwydte van 3:17 se woorde, ..al die dae van jou lewe". dus nader uitgewerk.

Die ilee vall gebrokenheid vind ook steun in die tipering van Henog se lewe. Hy leef maar omtrent die helfte van die tyd van die ander. Ons sou in die geval van so in godvresende persoon eerder in lang lewe verwag. lereg merk Keil'" egler op dal in lang lewe wel tyd gun vir berou en genade en dus vir die ontvangs van die seën van God, maar aan die ander kant. as ..the ills which have entered the world through sin are considered it is also a burden and trouble which (iod shortens for his chosen". As ons in gedagte hou dat Henog nic gesterf het nie. matar deur cod weggeneen is. is daar nie 'n spanning tussen dis feit dat Henog in betreklike kort lewe gehad het lerwyl $n$ lang lewe in die ().T. as in seèn van (jod beskou is nie. Die opmerking van Keil vind ook steun in die woorde van lameg dangaande Noag in 5:29: ..Dil is hy wat ons sal troos oor die moeitevolle arbeid van ons hande wat voorthom uit die aarde wat Jahwe 
vervloek het". Dic ,dae" was dus ook vir Henog moeilik, en sy vroee heengaan is "n verlossing uit daardic ..dae" na God toe.

Teenoor die cenheid van Gods werk wat vervat is in die herhaalde woord "dag" in die begin van dic geslagsregister (5:1.2) soos ook in $2: 4$ in verband met Gods skeppingswerk ... staan dus, in sterk teenstelling, die gebrokenheid van die menslike lewe soos vervat in die woord "dae". Hierdie gebrokenheid vind ook weerklank in die woorde oor die aarde se bestaan in 8:22: ..Van nou af sal, al die dae van die aurde, saaityd en oestyd, koue en hille. somer en winter. dag en nag nie ophou nie". Hier het ons wel "n genadedaad van God en 'n tempering van die vloek van die aarde (3:17), maar dit hef die vloek nie op nie en neem die mocitevolheid ook nie weg nie; dit plaas die dinge slegs binne perke sodat lic chaostosstande van die tyd voor die sondvloed nie weer sal voorkom nie. Die woorde ...lie vrees en die skrik vir julle sal wees oor al die diere van die aarde ...." $(9: 2)$ toon dat die gebroke toestand van die aarde nog voortduur.

Die woorde ..dag" en ..dae" in die cerste hoofstukke van (jenesis teken dus 'n besonder sterk teenstelling tussen die eenheid van Gorls werk wat vervat is in die herhaalde woord ..dag" in die begin van die geslagsregister $(5: 1.2) \ldots$ soos ook in $2: 4$ in verband met (iods skeppingswerk enersyds, en die lewe van die gevalle mens $(5: 4$ vlg.) en so ook die bestaan van die gevalle aarde $(8: 22)$, andersyds. 